\title{
A comparison of the assessment of mitral valve area by continuous wave Doppler and by cross sectional echocardiography
}

\author{
FRANCESCO LOPERFIDO, FRANCESCO LAURENZI, FABRIZIO GIMIGLIANO, \\ FAUSTINO PENNESTRI', LUIGI M BIASUCCI, CARLO VIGNA, \\ FRANCESCO DE SANTIS, ANGELA FAVUZZI, ELISABETTA ROSSI, \\ UGO MANZOLI \\ From the Department of Cardiology, Catholic University of Sacro Cuore, Rome, Italy
}

SUMMARY Transmitral pressure half time (PHT) was assessed by continuous wave Doppler in $\stackrel{\circ}{\stackrel{\circ}{\perp}}$ 44 patients with rheumatic mitral valve stenosis (14, pure mitral valve stenosis; 15, combined $>$ mitral stenosis and regurgitation; and 15 with associated aortic valve regurgitation). The mitral valve area, derived from transmitral pressure half time by the formula 220 /pressure half time, was $\vec{\oplus}$ compared with that estimated by cross sectional echocardiograpy. The transmitral pressure half time correlated well with the mitral valve area estimated by cross sectional echocardiography The correlation between pressure half time and the cross sectional echocardiographic mitral valve area was also good for patients with pure mitral stenosis and for those with associated mitral or aortic regurgitation. The regression coefficients in the three groups of patients were significantly® different. Nevertheless, a transmitral pressure half time of $175 \mathrm{~ms}$ correctly identified 20 of $21^{\Phi}$ patients with cross sectional echocardiographic mitral valve areas $<1.5 \mathrm{~cm}^{2}$. There were no false $\vec{\circ}$ positives. The Doppler formula significantly underestimated the mitral valve area determined by 3 cross sectional echocardiography by $28(9) \%$ in 19 patients with an echocardiographic area $>2$ ? $\mathrm{cm}^{2}$ and by $14.8(8) \%$ in 25 patients with area of $<2 \mathrm{~cm}^{2}$. In thirteen patients with pure mitral valve stenosis Gorlin's formula was used to calculate the mitral valve area. This was over- $\vec{D}$ estimated by cross sectional echocardiography by $0 \cdot 16(0 \cdot 19) \mathrm{cm}^{2}$ and underestimated by Doppler by $0 \cdot 13(0 \cdot 12) \mathrm{cm}^{2}$. Continuous wave Doppler underestimated the echocardiographic mitral valve area in patients with mild mitral stenosis. The Doppler formula mitral valve area $=220 /$ pressure half time was more accurate in predicting functional (haemodynamic) than anatomical (echo- $\frac{\circ}{3}$ cardiographic) mitral valve area.

Cross sectional echocardiography gives an accurate estimate of mitral valve area. ${ }^{1}$ When echocardiographic images are unsatisfactory, ${ }^{1-8}$ Doppler echocardiography is an alternative method of assessing the mitral valve area. ${ }^{9-16}$ The Doppler estimate of mitral valve area correlated well with the results of catheterisation even when there was mitral regurgitation or low cardiac output. ${ }^{131617}$ The results of heart catheterisation may not be the "gold standard"

Requests for reprints to Dr Francesco Loperfido, Istituto di Cardiologia, Universita' Cattolica S Cuore, Policlinico A Gemelli, L go Gemelli 8, 00168 Rome, Italy.

Accepted for publication 15 July 1986 for mitral valve area assessment because coexisten mitral regurgitation will lead to inaccuracy. ${ }^{18-2}$ Even in patients with pure mitral stenosis, cath O $_{0}$ eterisation is probably less accurate than cross sect tional echocardiography in predicting the anatomical mitral valve orifice. ${ }^{1}$

There are only a few studies in which Doppler and cross sectional echocardiographic estimates of mitraf $P$ valve area were compared, ${ }^{21} 22$ and the influence of 0 mitral regurgitation was not specifically consid웅 ered. ${ }^{22}$ We investigated the value of transmitrah pressure half time, determined by continuous wave Doppler, 910131617 in predicting the echow cardiographic mitral valve area in patients with 
mitral stenosis. We also examined the influence of associated mitral or aortic regurgitation on this comparison.

\section{Patients and methods}

\section{PATIENTS}

From June 1984 to the end of January 1985, 52 consecutive patients with rheumatic mitral stenosis were examined by cross sectional echocardiography and continuous and pulsed wave Doppler. Patients in whom cross sectional echocardiography showed thickened mitral leaflets, abnormal diastolic motion of the mitral leaflet, and a mitral valve area of $<3 \mathrm{~cm}^{21}$ were considered for subsequent analysis. Patients with previous mitral valvotomy, aortic valve stenosis, or a history of arterial hypertension were excluded. Nine patients were excluded because of inadequate echocardiographic studies and three because Doppler studies were unsatisfactory. Thus we studied 44 patients ( 38 women and 6 men) aged 24 to 77 years (mean 46 (12)). At the time of investigation 28 patients were in sinus rhythm and 16 in atrial fibrillation. We subdivided the patients into three groups on the basis of Doppler and heart catheterisation findings (when available): group 1 had pure mitral stenosis; group 2 had mitral stenosis and regurgitation; and group 3 had mitral stenosis (with or without mitral valve regurgitation) and aortic regurgitation.

\section{CROSS SECTIONAL ECHUCARDIOGRAPHIC AND} DOPPLER METHODS

Cross sectional echocardiographic and Doppler studies were performed by means of a real time phased-array system (Toshiba SSH-40A) connected to a Doppler unit (Toshiba SS-21B). Transducers with a frequency of 2.4 and $3.5 \mathrm{MHz}$ were used for imaging and pulsed wave Doppler and $2.4 \mathrm{MHz}$ for continuous wave Doppler.

Cross sectional echocardiography was performed by the standard technique. We assessed the mitral valve area from the parasternal short axis view, taking care to image the orifice from a transducer location that was perpendicular to the valve at the level of its maximal narrowing and at optimal gain settings. ${ }^{1}$ Mitral valve area was automatically calculated on the video screen by use of a built-in system of movable electronic callipers on the stop frame that showed mitral valve opening in early ventricular diastole. The inner margin of the orifice was traced. ${ }^{2} 5$

Transmitral flow was examined by continuous wave Doppler from the apex with the patient in the left lateral decubitus position. ${ }^{17}$ The Doppler signal reproduced as an audio signal and the spectral anal- ysis of frequencies was obtained in real time by fast Fourier transform. The maximum measurable frequency for continuous wave Doppler was $12 \mathrm{kHz}$. In all studies the cutoff frequency of the filter was $\mathbf{4 0 0}$ Hz. Care was taken to obtain spectral patterns with an uninterrupted high frequency profile. ${ }^{1323}$ Velocity profiles were recorded at a speed of $50 \mathrm{~mm} / \mathrm{s}$ on a Sony videotape recorder. Hard copies for subsequent analysis were reproduced with a strip chart recorder. In each study the incident Doppler beam was kept nearly perpendicular to mitral valve plane by means of intermittent cross sectional echocardiographic imaging. We did not correct for the Doppler flow angle.

We calculated the transmitral peak pressure drop $(\Delta \mathrm{P})$ by measuring the maximal velocity $(\mathrm{V})$ in early diastole and by use of the equation: $\Delta P=4 V^{2}$. The transmitral mean pressure drop was calculated from the curve that we obtained by calculating the pressure drop for several points during diastole. ${ }^{13} \mathrm{We}$ measured velocity at the upper limit of the frequency

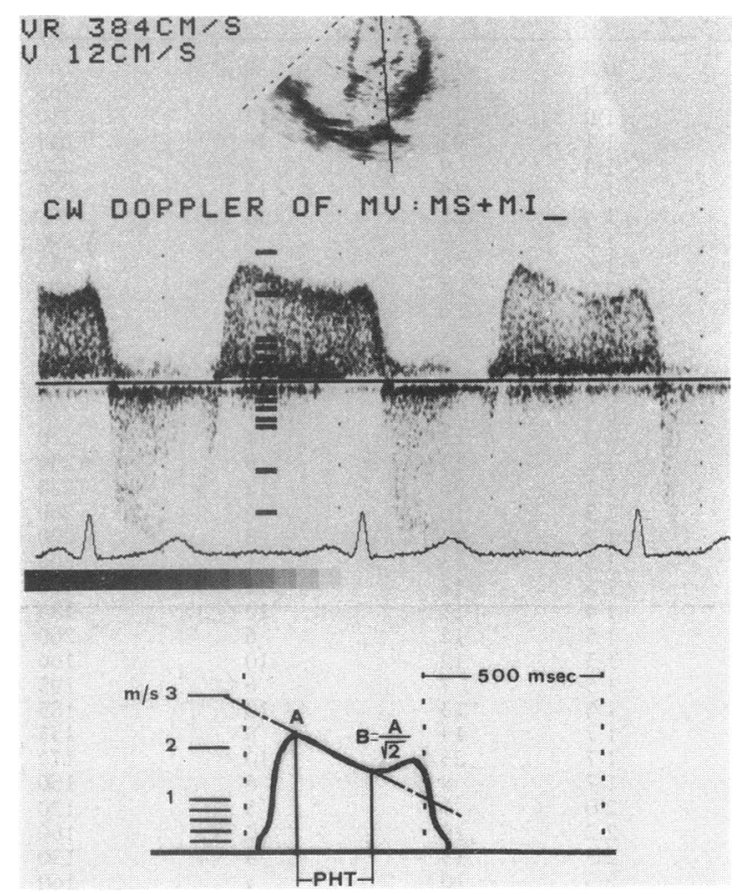

Fig 1 (Top) Transmitral flow velocity curve obtained by continuous wave Doppler from the apical approach. (The solid line within the echocardiographic image is the Doppler beam.) (Middle) Flow velocity profile; flow below the zero line in systole indicates mitral regurgitation. The first 5 bars above and below the zero line represent calibration of $0.2 \mathrm{~m} / \mathrm{s}$ and the next bars represent $1 \mathrm{~m} / \mathrm{s}$. (Bottom) Method for obtaining transmitral pressure half time(PHT). A, peak velocity; $B$, half peak pressure. 
profile. Peak and mean pressure drop were expressed as $\mathrm{mm} \mathrm{Hg}$. Atrioventricular pressure half time was obtained by dividing the peak velocity by 1.4 and by measuring the time from the peak velocity to the point at which this decrease in velocity was found (fig 1). ${ }^{17}$ Data were rounded to $5 \mathrm{~ms}$. Peak and mean pressure drops and pressure half time were measured as the mean of 10 consecutive cardiac cycles either in sinus rhythm or atrial fibrillation. ${ }^{13}$

Mitral and aortic regurgitation were assessed by pulsed wave Doppler. ${ }^{24-28}$ Mitral regurgitation was identified in apical four chamber and parasternal long axis views when a high-pitched, whistling audio signal was present within the left atrium for at least one third of systole. ${ }^{20-23}$ When a mitral regurgitant flow was audible we used a cross sectional echo- cardiographic image of the left atrial area to obtain a semiquantitative assessment of regurgitant flow dis $-\vec{c}$ tribution. Mitral regurgitation was graded as: $1+$ turbulence just behind mitral valve; $2+$, extension of turbulence to the inferior half of left atrium; and $3+$, turbulence spreading even further ${ }^{24}$ Aortic re-을. gurgitation was identified in apical right anteriors oblique (or equivalent) and parasternal long axis $\_$ views when there was diastolic turbulence within the्छ left ventricle. It was differentiated from mitral stenosis flow by: (a) locating the sample volume immedi- ately under the aortic leaflets; $(b)$ accurately timing the onset of turbulence before mitral valve opening by simultaneous $M$ mode echocardiographic record- -7 ing. ${ }^{24-26} \mathrm{~A}$ distribution of Doppler frequencies that was typical of the aortic regurgitation, in which at

Table Cross sectional echocardiographic, continuous wave Doppler echocardiographic, and heart catheterisation data in $\underset{\infty}{\infty}$ 44 patients with rheumatic mitral valve stenosis

\begin{tabular}{|c|c|c|c|c|c|c|c|c|c|}
\hline \multirow[b]{2}{*}{$\begin{array}{l}\text { Patient } \\
\text { No }\end{array}$} & \multicolumn{2}{|c|}{ Cross sectional } & \multicolumn{3}{|l|}{ Doppler } & \multicolumn{2}{|l|}{ Catheterisation } & \multirow[b]{2}{*}{$M R$} & \multirow[b]{2}{*}{$A R$} \\
\hline & $\begin{array}{l}M V A \\
\left(\mathrm{~cm}^{2}\right)\end{array}$ & $\begin{array}{l}\text { Peak gradient } \\
\text { ( } m m \mathrm{Hg})\end{array}$ & $\begin{array}{l}\text { Mean gradient } \\
(m m \mathrm{Hg})\end{array}$ & $\begin{array}{l}\text { PHT } \\
\text { (ms) }\end{array}$ & $\begin{array}{l}M V A \\
\left(\mathrm{~cm}^{2}\right)\end{array}$ & $\begin{array}{l}\text { Mean gradient } \\
(\mathrm{mm} \mathrm{Hg})\end{array}$ & $\begin{array}{r}M V A \\
\left(\mathrm{~cm}^{2}\right)\end{array}$ & & \\
\hline 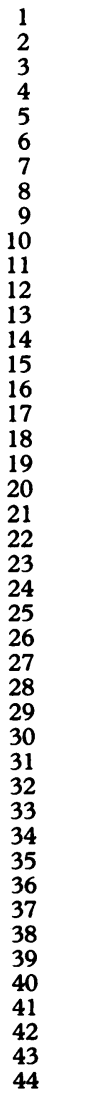 & 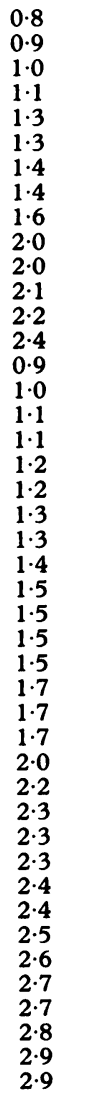 & $\begin{array}{r}13 \\
14 \\
19 \\
27 \\
9 \\
14 \\
21 \\
9 \\
8 \\
7 \\
9 \\
15 \\
8 \\
13 \\
23 \\
21 \\
14 \\
38 \\
10 \\
13 \\
13 \\
14 \\
13 \\
12 \\
12 \\
73 \\
13 \\
13 \\
23 \\
8 \\
19 \\
13 \\
10 \\
10\end{array}$ & $\begin{array}{r}9 \\
8 \\
17 \\
16 \\
7 \\
12 \\
15 \\
5 \\
5 \\
6 \\
7 \\
8 \\
6 \\
8 \\
21 \\
14 \\
9 \\
12 \\
6 \\
8 \\
11 \\
11 \\
10 \\
6 \\
10 \\
6 \\
10 \\
8 \\
10 \\
6 \\
5 \\
10 \\
5 \\
4 \\
6 \\
5 \\
10 \\
4 \\
7 \\
6 \\
6 \\
5 \\
7 \\
4\end{array}$ & $\begin{array}{l}260 \\
265 \\
210 \\
245 \\
220 \\
220 \\
200 \\
190 \\
155 \\
150 \\
140 \\
135 \\
120 \\
110 \\
240 \\
210 \\
250 \\
220 \\
200 \\
220 \\
200 \\
195 \\
185 \\
200 \\
160 \\
195 \\
185 \\
155 \\
170 \\
150 \\
120 \\
160 \\
130 \\
160 \\
160 \\
130 \\
130 \\
130 \\
150 \\
105 \\
145 \\
115 \\
105 \\
105\end{array}$ & $\begin{array}{l}0.8 \\
0.8 \\
1.0 \\
0.9 \\
1.0 \\
1.0 \\
1.1 \\
1.2 \\
1.4 \\
1.5 \\
1.6 \\
1.6 \\
1.8 \\
2.0 \\
0.9 \\
1.0 \\
0.9 \\
1.0 \\
1.1 \\
1.0 \\
1.1 \\
1.1 \\
1.2 \\
1.1 \\
1.3 \\
1.1 \\
1.2 \\
1.4 \\
1.3 \\
1.4 \\
1.8 \\
1.4 \\
1.7 \\
1.4 \\
1.4 \\
1.7 \\
1.7 \\
1.7 \\
1.5 \\
2.1 \\
1.5 \\
1.9 \\
2.1 \\
2.1\end{array}$ & $\begin{array}{c}8 \\
10 \\
\text { NA } \\
16 \\
8 \\
9 \\
10 \\
6 \\
6 \\
4 \\
8 \\
5 \\
7 \\
4 \\
17 \\
16 \\
13 \\
15 \\
10 \\
\text { NA } \\
16 \\
6 \\
\text { NA } \\
\text { NA } \\
9 \\
\text { NA } \\
18 \\
\text { NA } \\
12 \\
9 \\
6 \\
\text { NA } \\
\text { NA } \\
8 \\
\text { NA } \\
\text { NA } \\
15 \\
6 \\
6 \\
8 \\
\text { NA } \\
\text { NA } \\
8 \\
13 \\
\end{array}$ & $\begin{array}{l}1 \cdot 0 \\
0 \cdot 7 \\
\text { NA } \\
1 \cdot 0 \\
1 \cdot 4 \\
1 \cdot 2 \\
1 \cdot 2 \\
1 \cdot 3 \\
1 \cdot 6 \\
1 \cdot 7 \\
1 \cdot 7 \\
1 \cdot 6 \\
1 \cdot 9 \\
2 \cdot 1 \\
\text { NA } \\
\text { NA } \\
\text { NA } \\
\text { NA } \\
\text { NA } \\
\text { NA } \\
\text { NA } \\
\text { NA } \\
\text { NA } \\
\text { NA } \\
\text { NA } \\
\text { NA } \\
\text { NA } \\
\text { NA } \\
\text { NA } \\
\text { NA } \\
\text { NA } \\
\text { NA } \\
\text { NA } \\
\text { NA } \\
\text { NA } \\
\text { NA } \\
\text { NA } \\
\text { NA } \\
\text { NA } \\
\text { NA } \\
\text { NA } \\
\text { NA } \\
\text { NA } \\
\text { NA }\end{array}$ & 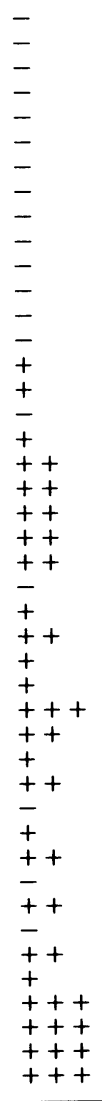 & $\begin{array}{l}- \\
- \\
- \\
- \\
- \\
- \\
- \\
- \\
- \\
- \\
- \\
- \\
+ \\
++ \\
- \\
+ \\
+ \\
+ \\
+ \\
+ \\
+ \\
+ \\
+ \\
+ \\
+ \\
+ \\
+ \\
+ \\
+ \\
+\end{array}$ \\
\hline
\end{tabular}

AR, aortic regurgitation; MVA, mitral valve area; MR, mitral regurgitation; PHT, pressure half time; NA, not available. 
decreasing diastolic pattern is accompanied by a corresponding audio signal, was also assessed by continuous wave Doppler. ${ }^{6}$ Artefacts due to excessive noise and wall movements were excluded. ${ }^{27-29}$

\section{CARDIAC CATHETERISATION}

Cardiac catheterisation was performed in 32 patients within 24 hours of the Doppler studies. In patients with pure mitral stenosis, mitral valve area was calculated by Gorlin's formula ${ }^{18}$ from left ventricular pulmonary capillary wedge pressure recordings and cardiac output was determined by the Fick method. Mitral and aortic regurgitation were assessed by standard angiographic techniques. No attempt was made to calculate mitral valve area in patients with mitral regurgitation. The haemodynamic and Doppler studies were not performed simultaneously.

\section{STATISTICAL ANALYSIS}

Cross sectional echocardiographic, continuous Doppler, and cardiac catheterisation data were measured by three different pairs of observers who were unaware of the results of the other studies. We took the mean of each pair of measurements. Mean (SD) interobserver variability was 3 (3) \% for the cross sectional echocardiographic mitral valve area and $5(4) \%$ for Doppler pressure half time; this resembles variability in previous studies. ${ }^{3031}$ Interobserver variability for the haemodynamic mitral valve area was $4(3) \%$. When appropriate we analysed the data by analysis of variance, paired and unpaired $t$ tests, linear regression, and the non- regression method for assessing agreement between different methods, recently described by Bland and Altman. ${ }^{32}$

\section{Results}

\section{PATIENT DATA}

Pulsed wave Doppler and angiographic data, when available, showed pure mitral stenosis in 14 patients, mitral stenosis and regurgitation in 15, and mitral stenosis and aortic regurgitation in 15 (10 with and 5 without mitral regurgitation). Mitral regurgitation was graded as $1+$ in nine patients, $2+$ in 11 , and $3+$ in five. Pulsed wave Doppler grading of mitral regurgitation was confirmed in 14 of 16 patients undergoing angiography. In two patients the angiographic grade of mitral regurgitation was slightly underestimated by pulsed wave Doppler. Cross sectional echocardiographic mitral valve area was $<1 \mathrm{~cm}^{2}$ in five patients, from 1 to $1.5 \mathrm{~cm}$ in 16 , and $>1.5 \mathrm{~cm}^{2}$ in 23. The table shows the cross sectional echocardiographic, pulsed and continuous wave Doppler, and catheterisation results.

The peak transmitral pressure drop ranged from 7 to $38 \mathrm{~mm} \mathrm{Hg}$ (mean (SD) $14.7(8)$ ), the mean transmitral pressure drop ranged from 4 to $21 \mathrm{~mm} \mathrm{Hg}$ (mean (SD) 7 (3.9)). Peak and mean pressure drops were not significantly different in the 19 patients with mitral stenosis and no mitral regurgitation (including five with aortic regurgitation) (cross sectional echocardiographic mitral valve area 1.6 $\left.(0.5) \mathrm{cm}^{2}\right)$ and in the 20 patients with associated $\mathrm{mi}-$

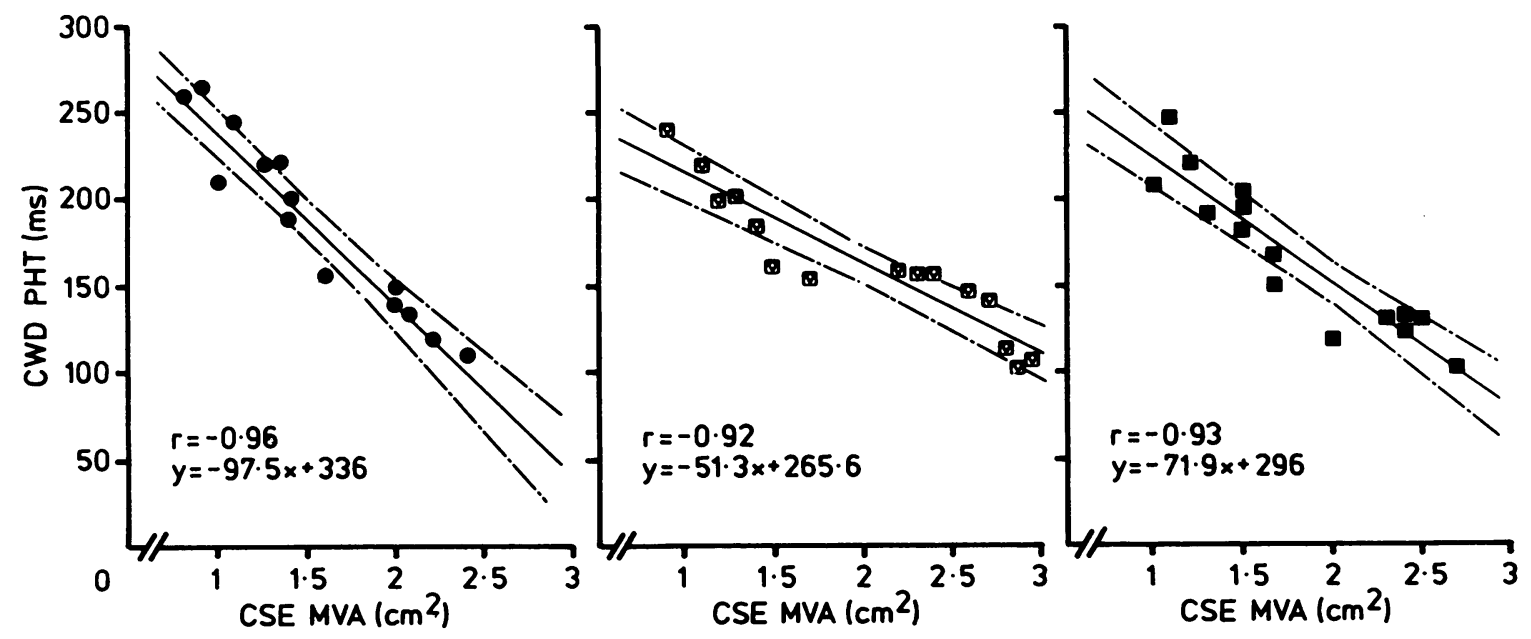

Fig 2 Regressions between continuous wave Doppler transmitral pressure half time (CWD PHT) and cross sectional echocardiographic mitral valve area (CSE MVA) in patients with pure mitral valve stenosis ( $O$ ), with associated mitral regurgitation ( $\square$ ), and with aortic regurgitation ( $(\mathbf{)})$. Broken lines indicate the confidence intervals of the regression line. The slope of regression in patients with pure mitral stenosis was significantly different from that in patients with associated mitral $(p<0.001)$ or aortic $(p<0.01)$ regurgitation. 


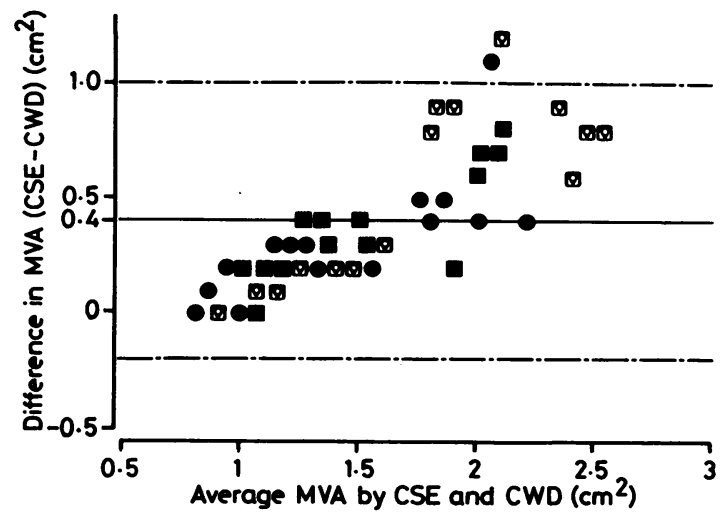

Fig 3 Agreement between cross sectional echocardiographic (CSE) and continuous wave Doppler (CWD) (220/PHT) estimates of mitral valve area (MVA). ${ }^{32}$ Difference in mitral valve area ( $y$ axis) plotted against the mean value of the two areas ( $x$ axis, average mitral valve area) in 44 patients with pure mitral stenosis or mitral stenosis associated with mitral or aortic regurgitation. Cross sectional echocardiography overestimated the Doppler area by $0.41 \mathrm{~cm}^{2}$ (solid line). Broken lines show $\pm 2 S D$ $\left(-0.2 \mathrm{~cm}^{2}\right.$ and $\left.+1 \mathrm{~cm}^{2}\right)$. The overestimation by cross sectional echocardiography increases with the size of the mitral valve area. Symbols as in fig 2.

tral regurgitation and with a comparable mitral valve area $\left(1.6\left(0.5 \mathrm{~cm}^{2}\right)\right.$ (peak pressure drop 12.2(5.7) vs $14.5(7.2) \mathrm{mm} \mathrm{Hg}$; mean pressure drop 8.4(3.9) vs $9 \cdot 3(3 \cdot 8) \mathrm{mm} \mathrm{Hg})$ ).
TRANSMITRAL PRESSURE DROP AND PRESSURE HALF TIME VERSUS CROSS SECTIONAL ECHOCARDIOGRAPHIC MITRAL VALVE AREA

The cross sectional echocardiographic mitral valve area correlated poorly with peak and mean trans mitral pressure drops $(r=-0.29$ and -0.44 re spectively). The correlation between continuous wave Doppler pressure half time and cross sectiona echocardiographic mitral valve area was goo $\vec{\Phi}$ $(r=-0.91 ; p<0.001)$. Figure 2 shows separate re $\overrightarrow{\bar{A}}$ gression lines for patients with pure mitral stenosif $(r=-0.96)$, for patients with mitral stenosis an $\Phi$ regurgitation $(r=-0.92)$, and for patients with as sociated aortic regurgitation $(r=-0.93)$. The slope of the regression line for patients with pure mitrat stenosis differed significantly from those of theे groups with associated mitral $(p<0.001)$ or aortie valve regurgitation $(p<0.01)$.

Mean transmitral pressure half time was significantly longer in patients with cross sectionat. echocardiographic mitral valve area $<1 \mathrm{~cm} \frac{\overline{2}}{c}$ $(230(27) \mathrm{ms})$ than in those with valve areas of frone 1 to $1.5 \mathrm{~cm}^{2}$ (205 (23) $\left.\mathrm{ms}\right)$ and $>1.5 \mathrm{~cm}^{2}$ (136 (20) ms) $(p<0.001)$. When a cross sectional echoe cardiographic mitral valve area of $1.5 \mathrm{~cm}^{2}$ was use to distinguish patients with severe stenosis and thos with less severe mitral stenosis, a Doppler pressure half time of $>175 \mathrm{~ms}$ correctly classified 20 of $2 \mathbb{P}$ patients with mitral valve area $<1.5 \mathrm{~cm}^{2}$. No patien $\overrightarrow{\widehat{\Phi}}$ with a cross sectional echocardiographic mitral valve area $>1.5 \mathrm{~cm}^{2}$ had mitral stenosis classified as severe by continuous wave Doppler.

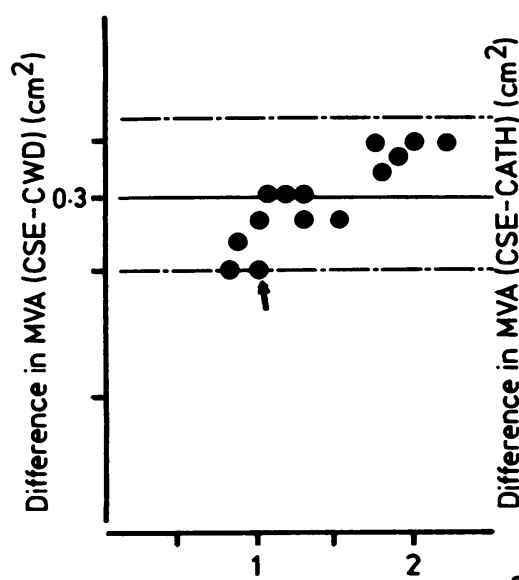

Average MVA by CSE and CWD (cm $\left.{ }^{2}\right)$ Average MVA by CSE and CATH $\left(\mathrm{cm}^{2}\right)$ Average MVA by CWD and CATH (cm 2$)$

Fig 4 Plot of the differences between cross sectional echocardiographic (CSE), continuous wave Doppler (CWD), and haemodynamic mitral valve area (Gorlin's formula) in patients with pure mitral valve stenosis (legend and symbols as in fig 3). The arrow indicates a patient with pure mitral stenosis in whom catheterisation was not performed. The haemodynamic area was overestimated by cross sectional echocardiography and underestimated by Doppler. Doppler and haemodynamic estimates, however, agreed more with each other than with echocardiography. Cath = catheterisation. 
CONTINUOUS WAVE DOPPLER VERSUS CROSS SECTIONAL ECHOCARDIOGRAPHIC ESTIMATES OF MITRAL VALVE AREA

We found that a cross sectional echocardiographic mitral valve area of $1 \mathrm{~cm}^{2}$ corresponded to a transmitral pressure half time (PHT) value of $220 \mathrm{~ms}$. This confirmed results previously reported by Hatle and Angelsen, who found a similar correspondence between cardiac catheterisation and Doppler data. ${ }^{17}$ The formula: mitral valve area $=220 /$ PHT (ms), however, underestimated the corresponding echocardiographic mitral valve area by $0.41(0.30) \mathrm{cm}^{2}$ (fig 3). The larger the orifice, the greater the underestimate: $0 \cdot 2(0 \cdot 12) \mathrm{cm}^{2}(15(8) \%$ of absolute mitral valve area) in the 25 patients with a cross sectional echocardiographic mitral valve area of $<2 \mathrm{~cm}^{2}$ and $0.70(0.26) \mathrm{cm}^{2}(28(9) \%)$ in the 19 patients with echocardiographic area of $>2 \mathrm{~cm}^{2}$ (12 with associated mitral valve regurgitation) ( $p<0.01$ ) (fig 3 ). The degree of underestimation was $0.30(0.15) \mathrm{cm}^{2}$ in patients with pure mitral stenosis, $0.56(0.41) \mathrm{cm}^{2}$ in those with combined mitral stenosis and regurgitation, and $0.40(0.23) \mathrm{cm}^{2}$ in the group with associated aortic regurgitation.

\section{ECHOCARDIOGRAPHIC AND DOPPLER}

\section{ESTIMATES VERSUS CARDIAC}

CATHETERISATION MITRAL VALVE AREAS IN

PATIENTS WITH PURE MITRAL STENOSIS

In fig 4 cross sectional echocardiographic and continuous wave Doppler estimates of mitral valve area in the 13 patients with pure mitral stenosis who underwent cardiac catheterisation are compared with the haemodynamic estimate. Though both cross sectional echocardiographic and Doppler estimates correlated closely with the Gorlin's estimate ( $r=0.96$ and 0.94 , respectively), cross sectional echocardiography overestimated the haemodynamic area by $0 \cdot 16(0 \cdot 19) \mathrm{cm}^{2}$ and Doppler underestimated it by $0.13(0.12) \mathrm{cm}^{2}(\mathrm{p}<0.01)$.

\section{Discussion}

Cross sectional echocardiography gives an accurate assessment of mitral valve area ${ }^{12-4}$ except in patients with suboptimal images. ${ }^{3-5}$ In some patients, however, there is a considerable difference between estimates of mitral valve area by cross sectional echocardiography and by cardiac catheterisation. ${ }^{4}$ This has been attributed to limitations of both techniques. ${ }^{1-8}$

Doppler echocardiography can also be used to assess mitral valve area by means of transmitral pressure half time 9101317 -that is the time required for the diastolic atrioventricular pressure gradient to fall to half its initial value. ${ }^{3334}$ This method has been validated against cardiac catheterisation. ${ }^{1617}$ Catheterisation, however, is not the gold standard for mitral valve area assessment. ${ }^{120-2333-35}$ Recently, Smith et al reported a good correlation between both Doppler and cross sectional echocardiography and the haemodynamic mitral valve area in patients with unoperated mitral stenosis. ${ }^{22}$ In those who had had mitral valvotomy Doppler was more accurate. ${ }^{22}$ The influence of associated mitral or aortic regurgitation on the agreement between Doppler and cross sectional echocardiography was not specifically evaluated in the study of Smith et al. ${ }^{22}$

We found that Doppler transmitral pressure half time correlated with the cross sectional echocardiographic estimate of mitral valve area. Like other groups, 910131617 we did not find that mitral or aortic regurgitation substantially influenced the degree of this correlation, though they did modify the slope of the regressions. As reported elsewhere, ${ }^{17}$ a transmitral pressure half time value of $>175 \mathrm{~ms}$ was specific in predicting a mitral valve area of $<1.5 \mathrm{~cm}^{2}$. Further prospective studies are needed to establish the sensitivity and specificity of this criterion.

Hatle et al used the empirical formula, 220/PHT, to determine the haemodynamic mitral valve area. $^{1317}$ This formula was reliable for estimating the cross sectional echocardiographic mitral valve area too. ${ }^{161722}$ Doppler formula and cross sectional echocardiographic estimates of mitral valve area did not agree completely in our study, however. We found that the Doppler method underestimated the echocardiographic mitral valve area by $15 \%$ in patients with valve area of $<2 \mathrm{~cm}^{2}$ and by $28 \%$ in those with valve area of $>2 \mathrm{~cm}^{2}$. There are several explanations for differences between our results and those of previous workers. ${ }^{161722}$ Firstly, we examined more patients with mild mitral stenosis or with associated severe mitral regurgitation than did previous studies. 13161722 Even though mitral regurgitation should not per se alter the Doppler estimate of mitral valve area, because transmitral pressure half time is independent of the absolute flow rate, ${ }^{17}$ we found that mitral regurgitation influenced the regression between pressure half time and echocardiograhic area. Others have reported that the Doppler formula is less accurate when flow rates are high ${ }^{36}$ or mitral regurgitation is present. ${ }^{37}$ In our study the degree of Doppler underestimation increased with mitral valve size. Since severe mitral valve regurgitation was seen only in those patients with a mitral valve area $>2 \mathrm{~cm}^{2}$, we could not establish whether valve size or severe mitral regurgitation was the major determinant of Doppler underestimation.

Second, cross sectional echocardiography, Doppler echocardiography, and cardiac cath- 
eterisation may not measure the same variable. The exact point at which narrowing of mitral valve complex is maximal may be missed by cross sectional echocardiography, generally in patients with previous commissurotomy. ${ }^{122}$ Extensive calcification or fibrosis of the submitral apparatus, however, may increase the transmitral gradient to more than the value determined at the level of the leaflet tips. ${ }^{1} 517$ This condition might result in a large discrepancy between echocardiographic and Doppler or cardiac catheterisation estimates of mitral valve area in patients with severe mitral stenosis, in whom the submitral apparatus is more frequently affected. ${ }^{1}$

The third reason for the disagreement between Doppler and echocardiographic estimates of mitral valve area may be that the empirical Doppler formula, mitral valve area $=220 / \mathrm{PHT}$, does not predict the true anatomical mitral valve area. In previous studies, cross sectional echocardiographic mitral valve area was on average $0.3 \mathrm{~cm}^{2}$ larger than the cardiac catheterisation estimate. ${ }^{48}$ It has been suggested that cross sectional echocardiography measures the anatomical mitral valve area, whereas cardiac catheterisation estimates the functional mitral valve area. ${ }^{122}$ Haemodynamic considerations suggest that the functional area will be somewhat smaller than the anatomical one. In our patients with pure mitral stenosis, Doppler and cardiac catheterisation estimates of mitral area, although not obtained simultaneously, agreed with each other more than with cross sectional echocardiography. Both Doppler and cardiac catheterisation underestimated the echocardiographic area especially in patients with mild mitral stenosis. The different composition of our study group may explain why our results differ from those of Smith et al who found that both Doppler and echocardiography overestimated the haemodynamic area in a group of patients who, according to Gorlin's formula, had mitral valve area of $\leqslant 1.6 \mathrm{~cm}^{2}$ (including a few with severe mitral regurgitation). ${ }^{22}$ Our data suggest that the Doppler formula, which is based on a hyperbolic relation between transmitral pressure half time and mitral valve area, is more accurate in predicting the functional mitral valve area, as assessed by cardiac catheterisation, than the anatomical one, as assessed by cross sectional echocardiography. Further studies are needed to evaluate a potential influence of this disagreement between Doppler and cross sectional echocardiography on the clinical decision for or against surgery in patients with moderate mitral valve stenosis.

\section{References}

1 Weyman AE. Cross-sectional echocardiography. Philadelphia: Lea and Febiger, 1982:146-73.

2 Henry WL, Griffith JM, Michaelis LL, McIntosh CL,
Morrow AG, Epstein SE. Measurement of mitră orifice area in patients with mitral valve disease by real-time two-dimensional echocardiography. Circ寄 lation 1975;51:827-31.

3 Nichol PM, Gilbert BW, Kisslo JA. Two-dimension echocardiographic assessment of mitral stenosis. Ci culation 1977;55:120-33.

4 Wann LS, Weyman AE, Feigenbaum H, Dillon J⿷ Johnston KW, Eggelton RC. Determination of mitro/ valve area by cross-sectional echocardiography. Ann Intern Med 1978;88:337-41.

5 Naito M, Morganroth J, Mardelli TJ, Chen CC, Dreÿ fus LS. Rheumatic mitral valve stenosis: cross se tional echocardiographic analysis. Am Heart
1980;100:34-40.

6 Marino P, Zanolla L, Perini GP, Salazzari GC, Conti Poppi A. Critical assessment of two-dimensionat echocardiographic estimation of the mitral valve are्g in rheumatic mitral valve disease: calcific deposits $\mathrm{P}$ the valve as a major determinant of the accuracy of the method. Eur Heart J 1981;2:197-203.

7 Schweizer P, Bardos P, Krebs W, et al. Morphometrie investigations in mitral stenosis using two diment. sional echocardiography. Br Heart $J$ 1982;48:54-60.

8 Glover MU, Warren SE, Vieweg WVR, Ceretto M Samtoy LM, Hagan AD. M mode and two dimensional echocardiographic correlation with findings catheterization and surgery in patients with mitra stenosis. Am Heart J 1983;51:98-102.

9 Holen J, Aaslid R, Landmark K, Simonsen S. Dete mination of pressure gradient in mitral stenosis wit a non-invasive ultrasound Doppler technique. Act Med Scand 1976;199:445-60.

10 Holen J, Aaslid R, Landmark K, Simonsen S, Ostre $T$. Determination of effective orifice area in mitrat stenosis from non-invasive ultrasound Doppler daû and mitral flow rate. Acta Med Scand 1977;201:83-8.

11 Kalmanson D, Veyrat C, Bouchareine F, Degroote AD Non-invasive recording of mitral valve flow velocit patterns using pulsed Doppler echocardiography application to diagnosis and evaluation of mitral valve. disease. Br Heart J 1977;39:517-28.

12 Hatle L, Brubakk A, Tromsdal A, Angelsen B. Non invasive assessment of pressure drop in mitral steno sis by Doppler ultrasound. $\mathrm{Br}$ Heart $J$ 1978; 40:131-40.

13 Hatle L, Angelsen B, Tromsdal A. Noninvasive assess ment of atrio-ventricular pressure half-time by Doppler ultrasound. Circulation 1979;60:1096-104:

14 Diebold B, Theroux P, Bourassa MG, et al. Non invasive pulsed Doppler study of mitral stenosis and mitral regurgitation: preliminary study. $\mathrm{Br}$ Heart 1979;42:168-75.

15 Thuillez C, Theroux P, Bourassa MG, et al. Pulsefक Doppler echocardiographic study of mitral stenosis Circulation 1980;61:381-7.

16 Stamm RB, Martin RP. Quantification of pressure gra dients and areas across stenotic valves by Dopple ultrasound. J Am Coll Cardiol 1983;2:707-18.

17 Hatle L, Angelsen B. Doppler ultrasound in cardiolog Physical principles and clinical applications. Philadej phia: Lea and Febiger, 1985;110-24.

18 Gorlin R, Gorlin SG. Hydraulic formula for calculatio 
of area of stenotic mitral valve, other cardiac valves and central circulatory shunts. Am Heart J 1951;41:1-29.

19 Selzer A, Willet FM, McCaughey J, Feichtmeir TV. Uses of cardiac catheterization in acquired heart disease. $N$ Engl J Med 1957;257:121-5.

20 Askenazy J, Carlson J, Alpert JS, Dexter L. Mitral valve area in combined mitral stenosis and regurgitation. Circulation 1976;54:480-3.

21 Denning K, Dacian S, Hall D, Rudolph W. Doppler echocardiographic, 2-dimensional echocardiographic and invasive hemodynamic determination of valve orifice area in mitral valve stenosis. A comparative study [Abstract]. J Am Coll Cardiol 1985;5:404.

22 Smith $M$, Handshoe $R$, Handshoe S, Kwan OL, De Maria AN. Comparative accuracy of twodimensional echocardiography and Doppler pressure half-time methods in assessing severity of stenosis in patients with and without prior commissurotomy. Circulation 1986;73:100-7.

23 Robson J, Flaxman JC. Measurement of the enddiastolic pressure gradient and mitral valve area in mitral valve stenosis by Doppler ultrasound. Eur Heart $J$ 1984;5:660-7.

24 Miyatake K, Nimura Y, Sakakibara H, et al. Localisation and direction of mitral regurgitant flow in mitral orifice studied with combined use of ultrasonic pulsed Doppler technique and two dimensional echocardiography. Br Heart $J$ 1982;48:449-58.

25 Veyrat C, Ameur A, Mas S, Lessana A, Abitbol G, Kalmanson D. Pulsed Doppler echocardiographic indices for assessing mitral regurgitation. Br Heart $J$ 1984;51:130-8.

26 Bommer WJ, Maspes R, Miller L, Mason DT, De Maria AN. Quantification of aortic regurgitation with two-dimensional Doppler echocardiography [Abstract]. Am J Cardiol 1981;47:412.

27 Esper R. Detection of mild aortic regurgitation by range-gated pulsed Doppler echocardiography. Am J Cardiol 1982;50:1037-43.
28 Veyrat C, Ameur A, Gourtchiglovian C, Lessana A, Abitbol G, Kalmanson D. Calculation of pulsed Doppler left ventricular outflow tract regurgitant index for grading the severity of aortic regurgitation. Am Heart $J$ 1984;108:507-15.

29 Richards KL, Cannon SR, Crawford MH, Sorensen S. Noninvasive diagnosis of aortic and mitral valve disease with pulsed Doppler spectral analysis. $\mathrm{Am} \mathrm{J}$ Cardiol 1982;51:1122-7.

30 Marino P, Zanolla L, Nidasio GP, Nicolosi GL, Fabbri A. Interpretative reproducibility of two dimensional echocardiographic images. Analysis of intraobserver and beat to beat reproducibility of the mitral valve orifice. Eur Heart $J$ 1983;4:733-7.

31 Gardin JM, Dabestani A, Matin K, Allfie A, Russell D, Henry WL. Reproducibility of Doppler aortic blood flow measurements: studies on intraobserver, interobserver and day-to-day variability in normal subjects. Am J Cardiol 1984;54:1092-8.

32 Bland JM, Altman DG. Statistical methods for assessing agreement between two methods of clinical measurement. Lancet 1986;i:307-10.

33 Libanoff AJ, Rodbard S. Evaluation of the severity of mitral stenosis and regurgitation. Circulation 1966;33:218-26.

34 Libanoff AJ, Rodbard S. Atrioventricular pressure half-time. Measure of mitral valve orifice area. Circulation 1968;38:144-50.

35 Seitz WS, Hosenpud J, Schutz R. An orifice formula independent of mitral pressure gradient for the evaluation of prosthetic mitral valve obstruction. Eur Heart $J$ 1984;5:932-40.

36 Sagar KB, Wann LS. Doppler mitral pressure halftime is not an independent predictor of mitral valve area [Abstract]. J Am Coll Cardiol 1986;7:61A.

37 Gonzales MA, Child JS, Krivokapich J. Quantification of mitral stenosis: a comparative study of twodimensional and Doppler echocardiography and intracardiac hemodynamics [Abstract]. J Am Coll Cardiol 1986;7:61A. 